\title{
A Comparative Study of Effect of Compatibilization Agent on Untreated and Ultrasonically Treated Waste Ground Rubber Tire and Polyolefin Blends
}

\author{
Jin Kuk Kim, Sung Hyo Lee, Maridass Balasubramanian \\ Research Institute of Industrial Technology, Gyeongsang National University
}

\begin{abstract}
The development of thermoplastic elastomer blends from waste tire powder and two polyolefins, Viz. maleic anhydride grafted polypropylene and LDPE, was studied. The polymer blends were processed using a twin-screw extruder equipped with a well-designed screw configuration. The blends studied contained a dispersed phase of waste rubber powder obtained from waste tire in a thermoplastic matrix. The effect of ultrasonic treatment on the rubber powder was compared. Contrary to our expectation, ultrasonically treated samples gave poor mechanical properties compared to untreated samples. Significant improvement in the mechanical properties was obtained with the addition of maleic anhydride-grafted styrene-ethylene-butylene-styrene (SEBS-g-MA) as a compatibilizer in treated and untreated waste tire powder / polyolefin blends.
\end{abstract}

Keywords: Waste tire powder; twin screw extruder, rubber recycling, compatibilizer.

\section{Introduction}

A large amount of valuable rubber is used throughout the world and after its product life is mainly reused as thermal energy source. A matter of particular concern is the recycling of these waste rubbers, such as waste rubber tires, not only because of the potential environmental hazard they represent but also because of the valuable hydrocarbon resource they can offer ${ }^{[1]}$. Conventional rubber products are thermosets based on a process of fabricating a part that involves an irreversible reaction between the rubber, sulfur and other chemicals to produce crosslinking between the rubber chains. It is not possible to restore thermoset rubber to its virgin form by use of heat or chemicals. Therefore, development of suitable technology for recycling waste rubbers is an important issue facing the rubber industry $^{[2,3]}$. One interesting method of recycling is by modification using an ultrasonic treatment ${ }^{[4]}$. In recent years, Isayev and his coworkers have carried out extensive studies on the application of ultrasound to polymer processing ${ }^{[5,6]}$. This continuous process also allows recycling of various types of rubbers and thermosets ${ }^{[7-9]}$. The ultrasonic waves at certain levels in the presence of pressure and heat, can break down the three-dimensional network in crosslinked rubber by the process of cavitation resulting in selective crosslinks breakage leaving the main chain mainly intact. As its most desirable consequence, ultrasonically devulcanized rubber becomes soft, enabling this material to be revulcanized or reprocessed by blending with thermoplastics and shaped, in very much the same way as the virgin rubber.

Blending recycled rubber with other materials has also been an attractive alternative in waste rubber recycling ${ }^{[10-13]}$. Its chief drawback has been the difficulty in obtaining adequate properties from the resultant blen$\mathrm{ds}^{[14]}$. Efforts to develop recycled rubber/plastic blends have followed earlier blending research on pure polymers that produced both thermoplastic elastomers and rubber-toughened plastics. Results of these numerous studies on virgin materials have provided criteria for a successful blend, the major criteria being that the two components must be thermodynamically incompatible enough to phase separate, but not so dissimilar that intimate intermixing cannot be accomplished. This criterion implies that the domain size of the dispersed phase must be small so that interfacial surface area is maximized, and the domain size leads to limits on the mismatch between the solubility parameters of the two components. Also, compatibilizers that act as interphase bridges between hard and soft phase are often helpful ${ }^{[15]}$. Of the various blends that have been reduced to practice, those based on waste tire powder/PP (polypropylene) and $\mathrm{PE}$ (polyethylene) combination has been by far the most successful ${ }^{[16]}$.

In this investigation, the effect of SEBS-g-MA compatibilizer on LDPE/ Waste tire powder and PP-g-MA/Waste tire powder blends was studied. Later, it is compared with ultrasonically treated waste tire powders. 


\section{Experimental}

\section{Materials}

The basic materials used in this study and their sources are as follows: Maleic anhydride-grafted polypropylene (PP-g-MA) RE 340B, (melt flow index of $9.2 \mathrm{~g}$ per $10 \mathrm{~min}$ and melting temperature of $160{ }^{\circ} \mathrm{C}$ ) was purchased from SK Corporation, South Korea. Maleic anhydride-grafted poly (styrene-block-ethylene-co-buylene-block-styrene) (SEBS-gMA), Kraton FG-1901X was obtained from Shell Chemical Co. Ltd. A linear density polyethylene (LDPE) extrusion grade 610A, (melt flow index of $4 \mathrm{~g}$ per $10 \mathrm{~min}$ and melting temperature of $109^{\circ} \mathrm{C}$ ) was obtained from Samsung Atofina Co. S.Korea. The waste tire rubber was produced by wet grinding method and its particle size was characterized to be 30 to $50 \mu \mathrm{m}$. In Figure 1, the bar in the SEM photo of the powder corresponds to $50 \mu \mathrm{m}$.

The waste rubber was composed of $48.5 \%$ which in turn is comprised of $25 \%$ natural rubber (NR) and $75 \%$ styreneco-butadiene rubber (SBR). It also contained $13.4 \%$ organic additives, $27.7 \%$ carbon block, and gave $10.4 \%$ ash content.

The blends ratio of the tire powder to PP-g-MA (or LDPE) was 65/35, as shown in Table 1. A Bau-Tech co-rotating twin-screw extruder $(\mathrm{D}=19 \mathrm{~mm}, \mathrm{~L} / \mathrm{D}=40)$ was used in the processing of all the blends. The screw speed was maintained at $100 \mathrm{rpm}$ and the temperatures profile of the extruder from feed to the die was 60/180/210/220/ $210 / 200{ }^{\circ} \mathrm{C}$ for all blends. The extrudate was cooled in a water bath and then granulated. The granular form was used for the preparation of tensile test specimens using injection molding at a temperature of $235{ }^{\circ} \mathrm{C}$ with a mold temperature of $30 \sim 35^{\circ} \mathrm{C}$ and injection pressure at $2000 \sim 2400 \mathrm{psi}$.

\section{Ultrasonic treatment}

The ground tire powder was fed into a single screw extruder $(\mathrm{L} / \mathrm{D}=30)$ with an ultrasonic system die attachment. The temperature of the extruder barrel was set at $150{ }^{\circ} \mathrm{C}$. The gap between the die and horn was varied from $1 \sim 3 \mathrm{~mm}$. The flow rate was $2.3 \mathrm{~g} / \mathrm{s}$, using a $1.5 \mathrm{KW}$ ultrasonic power supply with a converter and booster and horn. Ultrasonic treatment was carried out at a frequency of $20 \mathrm{KHz}$ and amplitudes of $10 \mu \mathrm{m}$ (Figure 2).

\section{Testing}

The mechanical properties (tensile strength and elongation at break) were measured using a Lloyd LR10K tensile testing

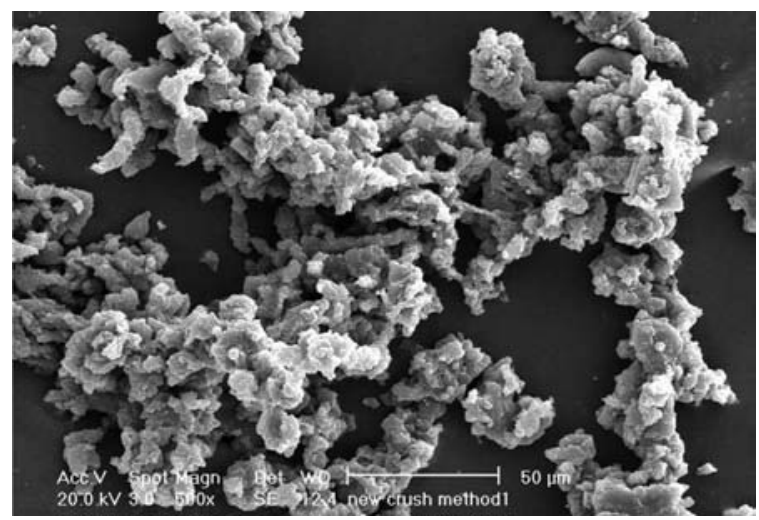

Figure 1. SEM photomicrograph of waste rubber powder.

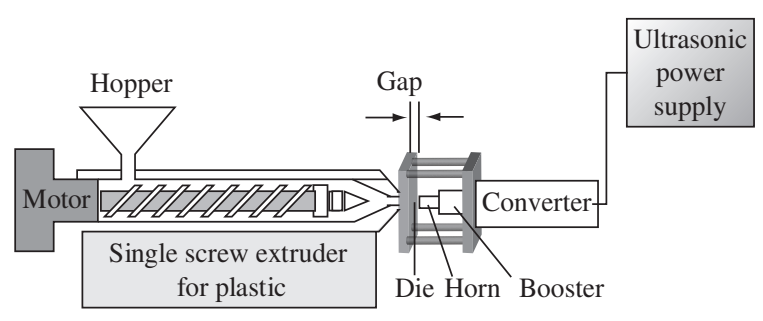

Figure 2. Ultrasonic equipment for treating waste tire powder.

machine in accordance with ASTM D412. The crosshead speed was $50 \mathrm{~mm} / \mathrm{min}$, and a load cell of $10 \mathrm{kN}$ capacity was used. For morphological observation, the molded samples were cryogenically fractured and also etched with p-xylene for $30 \mathrm{~min}$ to remove the olefin resin, washed repeatedly with water, and dried at $60^{\circ} \mathrm{C}$. The morphology of the samples was investigated using a scanning electron microscope (SEM) (Philips XL 30S, The Netherlands) after sputtering the samples with gold (JEOL JFC-1100E). The rheological properties of the samples were studied using a capillary rheometer model Galaxy V8052 with capillary length and diameter of 0.591 and 0.0276 respectively. Measurements were carried out at $250{ }^{\circ} \mathrm{C}$.

\section{Results and Discussion}

\section{Mechanical properties}

Generally, waste tire powder based thermoplastic blends have poor mechanical properties owing to the thermodynamic incompatibility ${ }^{[11]}$. Figure 3 shows the mechanical properties of the untreated and ultrasonically treated waste rubber blend with PP-g-MA and LDPE. The mechanical properties of the

Table 1. Formulation of blends.

\begin{tabular}{|c|c|c|c|c|c|c|c|c|c|c|c|c|}
\hline \multirow[t]{2}{*}{ Ingredients } & \multicolumn{6}{|c|}{ Untreated waste rubber } & \multicolumn{6}{|c|}{ Ultrasonically treated waste rubber } \\
\hline & $\mathbf{a}$ & b & c & d & $\mathbf{e}$ & f & $a_{1}$ & $\mathbf{b}_{1}$ & $c_{1}$ & $d_{1}$ & $\mathbf{e}_{1}$ & $\mathbf{f}_{1}$ \\
\hline Waste rubber & 65 & 65 & 65 & 65 & 65 & 65 & 65 & 65 & 65 & 65 & 65 & 65 \\
\hline PP-g-MA & 35 & - & 35 & - & 35 & - & 35 & - & 35 & - & 35 & - \\
\hline LDPE & - & 35 & - & 35 & - & 35 & - & 35 & - & 35 & - & 35 \\
\hline SEBS-g-MA & - & - & 5 & 5 & 10 & 10 & - & - & 5 & 5 & 10 & 10 \\
\hline
\end{tabular}


blends containing untreated waste rubber with PP-g-MA showed better results compared to those containing ultrasonically treated waste rubber. Similar behavior was also observed in LDPE blends. The poor properties could be explained as due to the rubber powders being degraded during ultrasonic treatment, although, there were no experiments done on the extent of degradation. The process of devulcanization using an ultrasonic treatment requires a high energy level to break down carbon-sulfur and sulfur-sulfur bond. Isayev and his group have done work on simulation of the network degradation during ultrasound devulcanization. They characterized the degree of devulcanization by the measurement of crosslink density and gel fraction of the devulcanized rubber in which they have claimed excellent agreement with experimental data for SBR and GRT ${ }^{[17]}$. They concluded that excessive treatment causes main chain breakage and therefore ultrasonic devulcanization causes significant degradation of polymer chain ${ }^{[18]}$. There were no physical crosslinks between the olefin polymers and waste rubber in our processing as shown in the SEM morphology which will be explained later. Figure $4 \mathrm{a}$ and $\mathrm{b}$ shows the effect of compatibilizer (SEBS-g-MA) on the mechanical properties of waste tire powder with PP-g-MA and LDPE blends. SEBS-g-MA dramatically improved the mechanical properties of the blends due
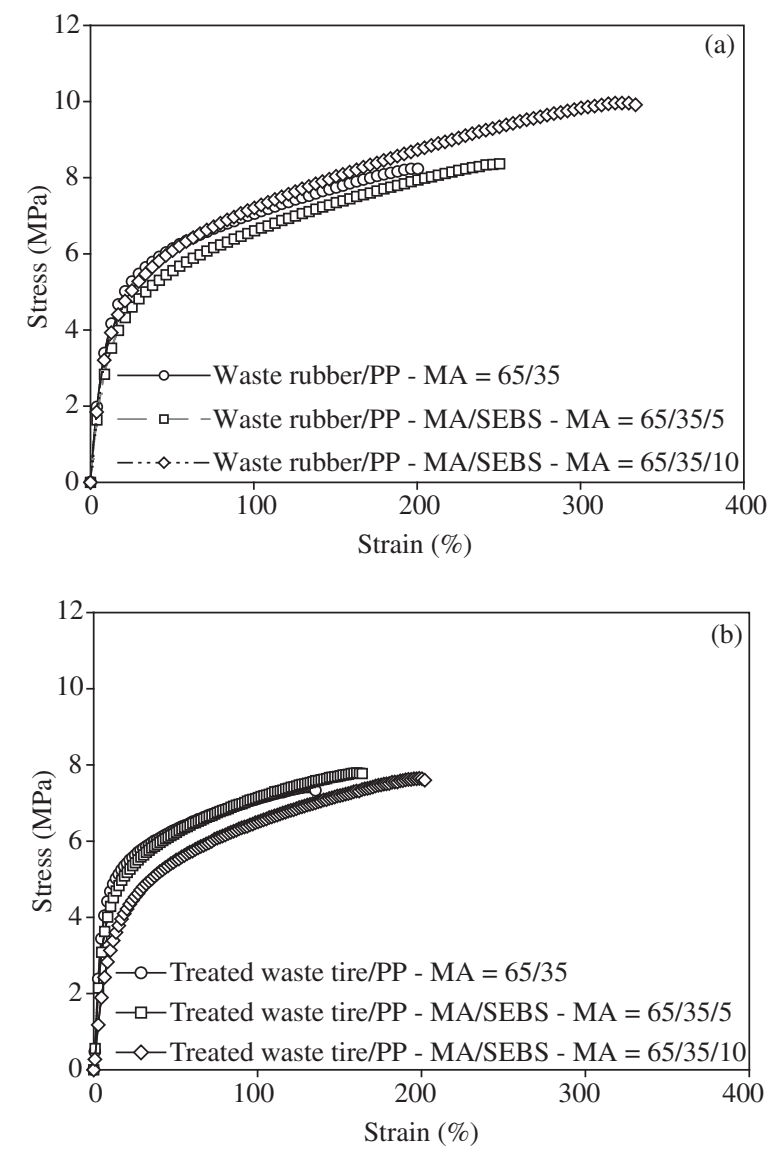

Figure 3. a) The effect of the SEBS-g-MA on the mechanical properties of untreated waste rubber/PP-g-MA blends; b) The effect of the SEBS-g-MA on the mechanical properties of treated waste rubber/PP-g-MA blends. to good compatibility of the two polymers. Figure 3 shows that in the case of polar compatibilizers used for WGRT/PPg-MA compounds, the functional polymer SEBS-g-MA gave the best mechanical properties of all the WGRT/PP-g-MA compounds. It has also been shown that PP has good compatibility with the EB (ethylene-co-butylene) block copolymer because of the repulsion effect ${ }^{[19]}$ of ethylene and butylene segments that might contribute to the improvement of the miscibility of PP with WGRT. Mainly, the reactive functional group Viz. MA (maleic anhydride) is in reaction with $-\mathrm{OH}$ (phenol group) on carbon black in the WGRT while the EB mid block of the SEBS copolymer has also good compatibility with PP, thereby the WGRT, PP-g-MA and compatibilizer (SEBS-g-MA) compound forms a stable three network system. In this case, it effectively bridges the GRT and the PP-g-MA phase. An increase in elongation at break, from 200 to $340 \%$ for untreated waste rubber/PP-g-MA blends, and from 125 to $220 \%$ for untreated waste rubber/LDPE, was observed. Similarly, improvement of properties was also found in the ultrasonically treated waste rubber for both PPg-MA and LDPE blends. Although there might have been some degradation in the rubber powder during the treatment, we are still expecting to increase the properties of the ultrasonically treated powder if curing agent was incorporated to the blends.

\section{Morphology}

Figure 5 shows the SEM micrographs of different olefin/untreated waste rubber and their blends with different amounts of SEBS-g-MA while Figure 6 shows the ultrasonically treated waste rubber with olefin resins. The results showed different morphologies for each blend type thereby indicating that each polymer behaves differently in response to untreated or ultrasonically treated waste tire. However, the blends containing SEBS-g-MA whether using untreated and ultrasonically treated waste rubber showed better morphology as can be seen in Figure $5 c, d, e, f$, and Figure $6 c_{1}, d_{1}, e_{1}$, and $\mathrm{f}_{1}$. Since there was no major difference in their morphologies between the plastic and rubber phases in untreated and treated blends, samples of PP-g-MA blends with SEBS-gMA were etched before examination was done. As can be seen in all blends, rubber particles constitute the dispersed phase with a continuous thermoplastic matrix. With the addition of compatibilizer, the surface properties of the blends were further improved. However, the effect of ultrasonically treatment was not clearly seen. As already mentioned, this may be due to higher degradation induced effect.

\section{Rheological properties}

The effect of ultrasonic treatment and SEBS-g-MA on the rheological behavior of the waste rubber blends with olefin resins is shown in Figure 7. The figure shows that the shear viscosity strongly depends on the kind of olefin resin rather than the blends ratio and whether the waste rubber was treated or not. In all cases, the apparent viscosity decreases with 

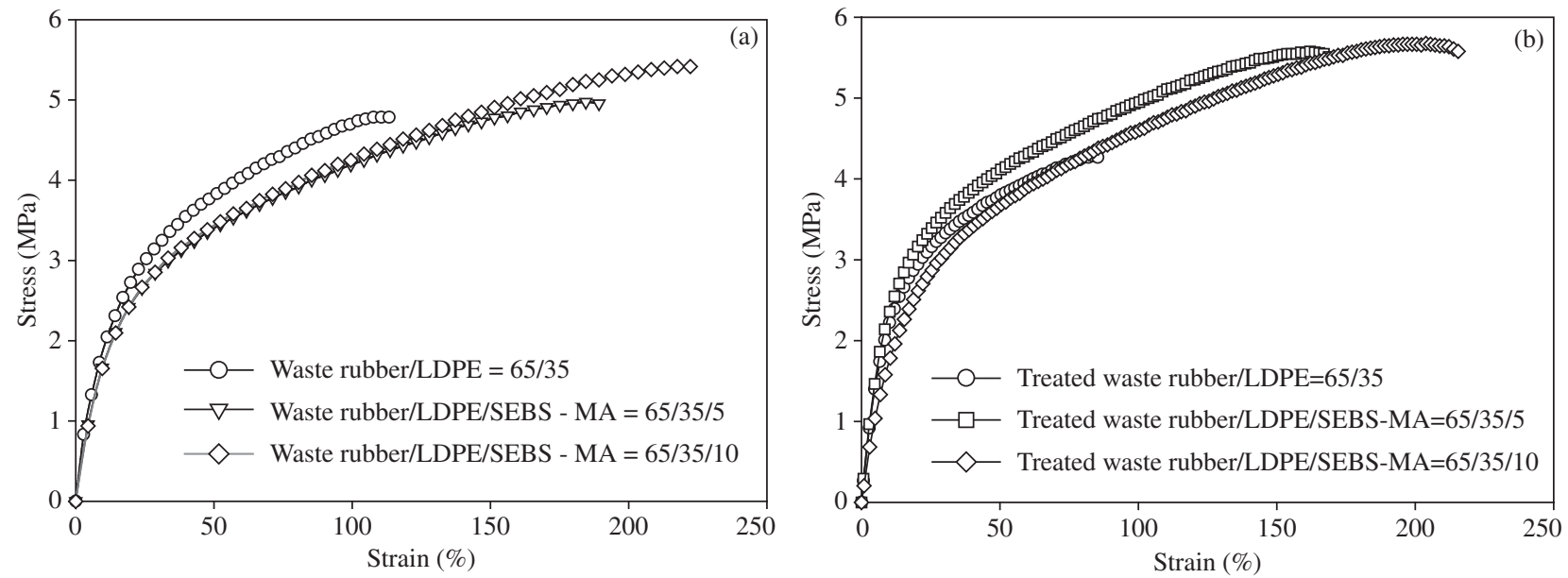

Figure 4. a) The effect of the SEBS-g-MA on the mechanical properties of untreated waste rubber/LDPE blends; b) The effect of the SEBS-g-MA on the mechanical properties of treated waste rubber/LDPE blends.
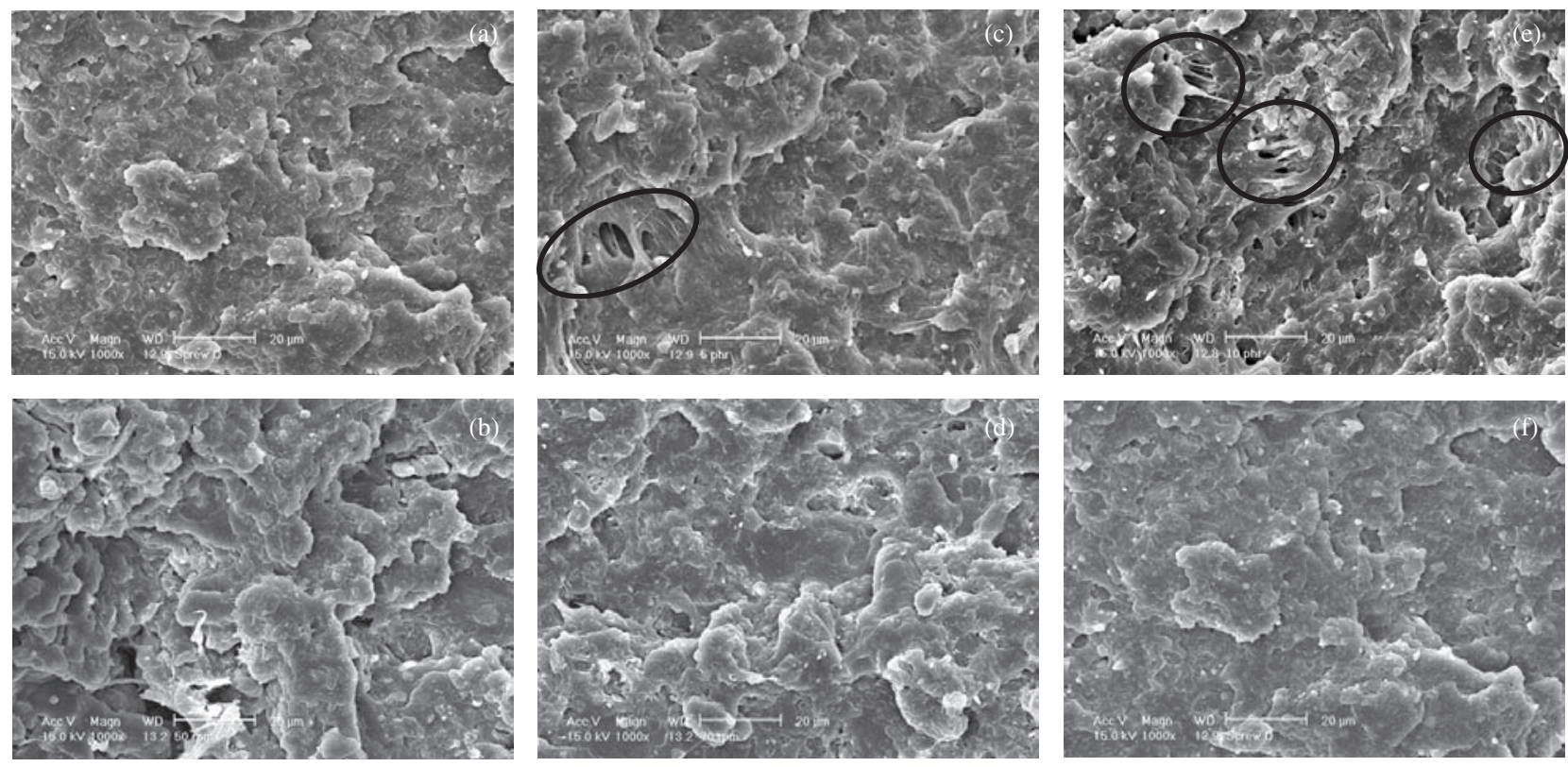

Figure 5. SEM micrographs of olefin resins blended with untreated waste rubber and their blends with different amount of SEBS-g-MA content. a) waste rubber : PP-g-MA (65:35); c) 65:35, 5\% SEBS-g-MA; e) 65:35, $10 \%$ SEBS-g-MA; b) waste rubber : LDPE (65:35); d) 65:35, 5\% SEBS-g-MA; f) 65:35, 10\% SEBS-g-MA. The bar in the figure corresponds to $20 \mu \mathrm{m}$.

increase in the apparent shear rate indicating a pseudoplastic behavior. It is obvious that the thermoplastic elastomer blends showed shear thinning behavior, which follows the power law model over the entire range of shear rates. These were attributed to the formation of crosslinks between the rubber chains within the rubber particles, which increases their stability toward shear breakdown during mixing, and therefore, less reduction in the shear viscosity of the blends.

\section{Conclusions}

The purpose of this study is to develop a thermoplastic elastomer blend of waste rubber and olefins polymer. Emphasis on the effect of compatibilizer (SEBS-g-MA) on their properties with respect to untreated and ultrasonically treated waste rubber with olefins was also studied. The general findings in this paper suggested that addition of compatibilizer in the blends containing untreated or ultrasonically treated waste and PP-g-MA resin dramatically improved the mechanical properties and the surface morphology clearly showed the rubber forms a dispersed phase with a continuous matrix. But, the resultant mechanical properties were poor for ultrasonically treated rubber due to possible degradation during ultrasonic treatment. However, an increase in properties was observed with the addition of compatibilizer. Untreated waster rubber gave good properties with PP-g-MA as matrix than the LDPE. The shear viscosity of the blends was strongly dependent on the type of thermoplastic resin rather than waste rubber/olefin resins blends. All the blends exhibited shear thinning behavior since the crosslinks formed between the 



Figure 6. SEM micrographs of olefin resins blended with ultrasonically treated waste rubber and their blends with different amount of SEBS-g-MA content. $a_{1}$ ) waste rubber : PP-g-MA (65:35); $\left.c_{1}\right)$ 65:35, 5\% SEBS-g-MA; $\left.e_{1}\right)$ 65:35, 10\% SEBS-g-MA; $b_{1}$ ) waste rubber : LDPE (65:35); d $)$ 65:35, 5\% SEBS-g-MA; and $\mathrm{f}_{1}$ ) $65: 35,10 \%$ SEBS-g-MA. The bar in the figure corresponds to $20 \mu \mathrm{m}$.
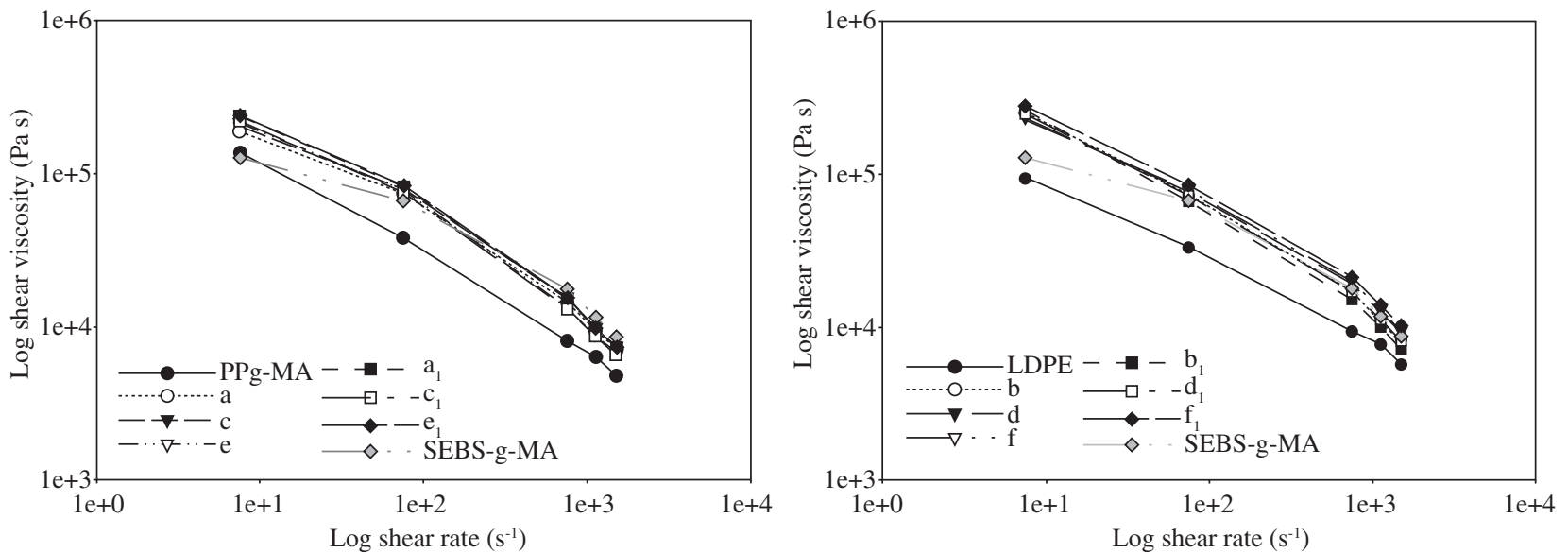

Figure 7. Shear viscosity of rheological property with shear rate of waste rubber blends for different olefin resins and blend ratios at $100 \mathrm{rpm}$.

rubber in the rubber particles increases their stability toward shear breakdown during mixing and thus, resulted to the reduction in the shear viscosity.

\section{Acknowledgments}

This study was supported by the Resource Recycling R\&D Center, 21C Frontier R\&D Program.

\section{References}

1. Maridass, B. \& Gupta, B. R. - Polym. Test, 23, p. 377 (2004).

2. Adhiikari, B.; De, D. \& Maiti, S. - Prog. Polym. Sci., 25, p. 909 (2000).
3. Naskar, A. K.; Bhowmick, A. K. \& De, S. K. - J. Appl. Polym. Sci., 84, p. 622 (2002).

4. Yun, J.; Isayev, A. I.; Kim, S. H. \& Tapale, M. - J. Appl. Polym. Sci., 88, p. 434 (2003).

5. Hong, C. K. \& Isayev, A. I. - J. Polym. Sci., 79, p. 2340 (2001).

6. Isayev, A. I.; Yashanov, S. P.; \& Chen, J. - J. Appl. Polym. Sci., 59, p. 803 (1996).

7. Isayev, A. I. - US Patent 5258413 (1993).

8. Isayev, A. I. - US Patent 5284625 (1994).

9. Ghose, S.; Isayev, A. I. \& Von Meerwall, E. - Polymer, 45, p. 3709 (2004).

10.Coran, A. Y. - "Thermoplastic elastomeric Rubber-Plastic blends", in: Handbook of Elastomers, cap.10, Bhow- 
mick, A. K. \& Stephens, H. L., (ed.), Marcel Dekker Inc., New York (2001).

11.Fuhrmann, I. \& Karger-Kocsis, K. - J. Appl. Polym. Sci., 89, p. 1622 (2003).

12.Scaffaro, R.; Dintcheva, N. T.; Nocilla, M. A. \& La Mantia, F. P. - Polym. Degr. Stabil., 90, p. 281 (2005).

13.Ismail, H. \& Suryadiansyah - Polym. Test., 21, p. 389 (2002).

14.Liu, H.; Mead, J. L. \& Stacer, R. G. - "Compatibilization approaches for recycled rubber/thermoplastic blending", in: International SAMPE Technical Conference, p.386 (2000).
15.Feldman, D. - J. Macr. Mol. Sci., Part A - Pure and Appl. Chem., 42, p. 587 (2005).

16. Abreu, F. O. M. S.; Forte, M. M. C.; Liberman, S. A. - J. Appl. Polym. Sci., 95, p. 254 (2005).

17.Tapale, M. \& Isayev, A. I. - J. Appl. Polym. Sci., 70, p. 2007 (1998).

18.Tukachinsky, A.; Schworm, D. \& Isayev, A. I. - Rubber Chem. Technol., 169, p. 92 (1996).

19.Setz, S.; Stricker, F.; Kressler, J.; Duschek, T. \& Mulhaupt, R. - J. Appl. Polym. Sci., 59, p. 1117 (1996).

Enviado: 23/01/06

Reenviado: $13 / 06 / 06$

Aprovado: 20/08/06 